\section{AB0591 SLE RES PONDER INDEX (SRI) UNDERESTIMATES CLINICAL RESPONSE IN MUSCULOSKELETAL SYSTEMIC LUPUS ERYTHEMATOSUS}

K. Mahmoud ${ }^{1,2}$, A. Zayat ${ }^{1,2}$, M.Y. Md Yusof ${ }^{1,2}$, E. Hensor ${ }^{1,2}$, P.G. Conaghan ${ }^{1,2}$, P. Emery ${ }^{1,2}, \mathrm{E}$ Vital $^{1,2}{ }^{1}{ }^{1}$ Leeds Institute of Rheumatic and Musculoskeletal Medicine, University of Leeds, University of Leeds; ${ }^{2}$ NIHR Leeds Biomedical Research Centre, Leeds Teaching Hospitals NHS Trust, LEEDS, UK

Background: Musculoskeletal (MSK) manifestations are common in SLE. Many recent clinical trials were negative or had small benefits vs. placebo. SRI is a common primary endpoint but has not been independently validated. Ultrasound is an objective measure of synovitis validated in inflammatory arthritis.

Objectives: To compare the responsiveness of clinical outcome measures with ultrasound in MSK-SLE.

Methods: 20 SLE patients meeting SLICC 2012 criteria with inflammatory MSK symptoms were studied with clinical assessment (BILAG2004, SLEDAI-2K over 30 days, patient and physician VAS, symptomatic, tender and swollen joint counts in 28 joints) and MSK ultrasound (grey scale and power Doppler scores, number of abnormal joints) at 0, 2, and 4 weeks after $120 \mathrm{mg} \mathrm{IM}$ depomedrone. Change in each variable was measured using Wilcoxon matched pairs and effect sizes( $\mathrm{r}=\mathrm{Z} /$ sqrt(2N) compared using Cohen (1988) criteria. Changes were compared for SRI4 responders and non-responders.

Results: All patients were ANA positive, CCP negative and female. At baseline, $15 / 20$ had clinical synovitis. The others had either ultrasound synovitis (GS in 18/ 20 , PD in 17/20) or $>60$ min EMS. 19/20 patients scored 4 points on SLEDAl for musculoskeletal involvement, BILAG scores were $A$ in $7 / 20$, B in $8 / 20$, and $C$ in $5 /$ 20. MSK-SLEDAI score improved in 9/20 at 4 weeks, MSK-BILAG improved in 16/ 20. For changes, see table 1.

Abstract AB0591 - Table 1

\begin{tabular}{|c|c|c|c|c|c|c|}
\hline & & $\begin{array}{c}\text { No. } \\
\text { pairs }\end{array}$ & $\mathbf{P}$ & Z & $\begin{array}{c}\text { Effect Size } \\
\mathbf{r}\end{array}$ & $\begin{array}{l}\text { Cohen } \\
\text { Criteria }\end{array}$ \\
\hline Week 0 - Week & PhysVAS & 16 & 0.001 & -3.409 & -0.603 & Large \\
\hline \multirow[t]{7}{*}{2} & GS Score & 16 & 0.002 & -3.13 & -0.571 & Large \\
\hline & US Joints & 16 & 0.011 & -3.160 & -0.559 & Large \\
\hline & PD Score & 16 & 0.002 & -3.099 & -0.548 & Large \\
\hline & SymJC & 10 & 0.047 & -1.988 & -0.445 & Medium \\
\hline & Pt VAS & 16 & 0.016 & -2.409 & -0.426 & Medium \\
\hline & SJC & 16 & 0.059 & -1.889 & -0.334 & Medium \\
\hline & TJC & 15 & 0.274 & -1.093 & -0.200 & Small \\
\hline Week 0 - Week & PhysVAS & 20 & $<0.001$ & -3.388 & -0.593 & Large \\
\hline \multirow[t]{9}{*}{4} & MSK BILAG & 20 & 0.008 & -3.643 & -0.576 & Large \\
\hline & PD Score & 20 & $<0.001$ & -3.627 & -0.573 & Large \\
\hline & US Joints & 20 & 0.001 & -3.627 & -0.573 & Large \\
\hline & GS Score & 20 & $<0.001$ & -3.503 & -0.554 & Large \\
\hline & $\begin{array}{l}\text { MSK- } \\
\text { SLEDAI }\end{array}$ & 20 & 0.003 & -3.000 & -0.474 & Medium \\
\hline & TJC & 20 & 0.007 & -2.683 & -0.424 & Medium \\
\hline & SymJC & 14 & 0.010 & -2.576 & -0.487 & Medium \\
\hline & SJC & 20 & 0.007 & -2.425 & -0.383 & Medium \\
\hline & PtVAS & 20 & 0.020 & -2.331 & -0.369 & Medium \\
\hline
\end{tabular}

19 patients with MSK-SLEDAl=4 at baseline were grouped into SRI- 4 responders $(n=9)$ and non-responders $(n=10)$. There were large effect sizes for improvement in TJC and SJC in responders ( $\mathrm{r}=-0.505$ and -0.492 respectively) and medium effect sizes in non-responders $(-0.365$ and -0.331$)$. For ultrasound, large effect sizes for improvements in both grey scale and power Doppler were observed in both responders $(r=-0.517$ and -0.564$)$ and nonresponders $(r=-0.629$ and -0.596$)$.

Conclusions: In MSK-SLE, ultrasound was the variable most consistently sensitive to change. All commonly used clinical variables significantly improved by week 4 but there was variation in responsiveness between them. BILAG-2004 and physician VAS had similar responsiveness to ultrasound. SRI-4 underestimated response, with substantial objective improvements in synovitis in SRI-4 non-responders. Developing organ-specific outcome measures may improve the ability to measure treatment effects in SLE clinical trials.

Disclosure of Interest: None declared

DOI: 10.1136/annrheumdis-2018-eular.2919

\section{$\mathrm{AB} 0592$}

IMPAIRMENT IN HAND STRENGTH, DEXTERITY AND ACTIVITIES OF DAILY LIVING PERFORMANCE IN PATIENTS WITH SYSTEMIC LUPUS ERYTHEMATOSUS: RESULTS OF A CROSS-SECTIONAL STUDY

K. Keramiotou $^{1}$, C. Anagnostou ${ }^{2}$, A. Galanos ${ }^{3}$, P. Sfikakis ${ }^{1}$, M.G. Tektonidou ${ }^{1}$. ${ }^{1}$ First Department of Propaedeutic and Internal Medicine, Medical School, National and Kapodistrian University of Athens; ${ }^{2}$ General Hospital of Elefsis 'Thriasio';

${ }^{3}$ Medical School, National and Kapodistrian University of Athens, Athens, Greece

Background: Systemic lupus erythematosus (SLE) is a prototypic autoimmune disease affecting multiple systems. To date a small number of studies have assessed the hand function and performance of daily activities in SLE ${ }^{1}$.

Objectives: To examine the grip and pinch hand strength, the dexterity, and the performance of Activities of Daily Living (ADL) in SLE patients compared with healthy controls.

Methods: 197 SLE patients $(48,03 \pm 12,76,88,3 \%$ female) and 100 healthy controls $(47,87 \pm 12,77,86 \%$ female $)$, matched by age and gender, were enrolled in the study. Both groups were assessed by hand grip and pinch grip strength, dexterity and ADL performance tests. Hand grip strength was measured by Jamar dynamometer, and pinch grip strength by pinch gauge, in both hands. Dexterity was measured by purdue pegboard test. Disabilities of the Arm, Shoulder and Hand (DASH) questionnaire and Health Assessment Questionnaire (HAQ) were used in order to determine the difficulties in ADLs.

Results: Hand grip strength, both lateral and jaws pinch grip strength, and dexter ity, were significantly impaired $(p<0,001)$ in both hands of SLE patients compared to healthy subjects (table 1). DASH questionnaire $(19.78 \pm 20.93$ vs $2.43 \pm 2.9$ $\mathrm{p}<0.001)$ and Health Assessment Questionnaire score (HAQ) $(0.41 \pm 0.52$ vs 0.03 $\pm 0.52, p<0.001)$ were also significantly different between SLE patients and healthy controls.

Abstract AB0592 - Table 1

\begin{tabular}{lcccccc}
\hline & \multicolumn{3}{c}{ Right Hand } & & \multicolumn{3}{c}{ Left Hand } & \\
& $\begin{array}{l}\text { Patient } \\
\text { group }\end{array}$ & $\begin{array}{c}\text { Control } \\
\text { group }\end{array}$ & P value & $\begin{array}{c}\text { Patient } \\
\text { group }\end{array}$ & $\begin{array}{c}\text { Control } \\
\text { group }\end{array}$ & P value \\
\hline Grip Strength & 25.59 & 30.89 & $<0.001$ & 24.54 & 29.56 & $<0.001$ \\
& \pm 9.12 & \pm 9.00 & & \pm 9.80 & \pm 9.21 & \\
Tip to tip Pinch & $3.94 \pm 2.03$ & $4.25 \pm 1.66$ & 0.194 & $3.45 \pm 1.73$ & $4.11 \pm 1.55$ & 0.002 \\
Strength & & & & & & \\
Lateral Pinch & $6.03 \pm 2.12$ & $7.24 \pm 1.85$ & $<0.001$ & $5.52 \pm 1.98$ & $6.66 \pm 1.93$ & $<0.001$ \\
Strength & & & & & & \\
Jaws Pinch & $4.68 \pm 1.99$ & $5.86 \pm 1.93$ & $<0.001$ & $4.37 \pm 1.94$ & $5.62 \pm 1.80$ & $<0.001$ \\
Strength & & & & & & \\
Purdue Score & 13.09 & 14.28 & $<0.001$ & 12.42 & 13.10 & $<0.001$ \\
& \pm 2.58 & \pm 2.58 & & \pm 2.16 & \pm 2.30 & \\
\hline
\end{tabular}

All values are presented as mean $\pm \mathrm{SD}$

Conclusions: These findings demonstrate that SLE patients have lower grip, pinch strength and dexterity and more difficulties in ADL performance. These find ings underline the need to develop specific hand therapy programs for SLE patients.

\section{REFERENCES:}

[1] Johnsson PM, Sandqvist G, Nilsson JA, et al. Hand function and performance of daily activities in systemic lupus erythematosus: a clinical study. Lupus 2015;24:827-834

Disclosure of Interest: None declared DOI: 10.1136/annrheumdis-2018-eular.6422 